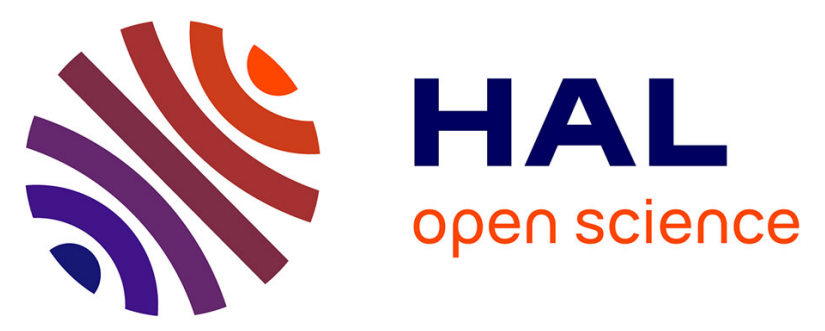

\title{
Performance improvement of partially shaded PV array using magic square view topology to mitigate the mismatching power losses
}

\author{
Lahcen El Iysaouy, M'hammed Lahbabi, Abdelmajid Oumnad
}

\section{To cite this version:}

Lahcen El Iysaouy, M'hammed Lahbabi, Abdelmajid Oumnad. Performance improvement of partially shaded PV array using magic square view topology to mitigate the mismatching power losses. International Meeting on Advanced Technologies in Energy and Electrical Engineering (IMAT3E'18), Nov 2018, Fez, Morocco. hal-01951254

\section{HAL Id: hal-01951254 \\ https://hal.science/hal-01951254}

Submitted on 11 Dec 2018

HAL is a multi-disciplinary open access archive for the deposit and dissemination of scientific research documents, whether they are published or not. The documents may come from teaching and research institutions in France or abroad, or from public or private research centers.
L'archive ouverte pluridisciplinaire $\mathbf{H A L}$, est destinée au dépôt et à la diffusion de documents scientifiques de niveau recherche, publiés ou non, émanant des établissements d'enseignement et de recherche français ou étrangers, des laboratoires publics ou privés. 


\title{
Performance improvement of partially shaded PV array using magic square view topology to mitigate the mismatching power losses
}

\author{
$1 *$ Lahcen El Iysaouy, ${ }^{2}$ Mhammed Lahbabi, ${ }^{1}$ Abdelmajid Oumnad
}

\section{*lahcen.eliysaouy@um5s.net.ma}

\author{
${ }^{1}$ ERSC formerly known as LEC, research Center E3S, EMI, Mohammed V University in \\ Rabat, BP765 Agdal, Rabat, Morocco \\ ${ }^{2}$ Laboratory of Signals, Systems, and Components, Sidi Mohamed Ben Abdellah University, \\ Fez, Morocco
}

Partial Shading Conditions (PSCs) decreases the output power from Photovoltaic (PV) arrays and represents multiple Maximum Power Points (MPPs) on output characteristics P-V, due to mismatching power losses between the PV panels. The main aim of This paper is to model, simulate, and enhance the performance of two PV array configuration namely Total Cross Tied (TCT) and proposed configuration Magic Square View (MSV) of size $9 \times 9$ PV array [1]-[4], which is $81 \mathrm{PV}$ modules in the total considered for this study under Short Wide shading patterns in order to extract the maximum power. The investigation of the enhancement of PV array configurations is carried out with regard to the comparison of the Global peak of outlet power (GP) of the proposed topology and TCT configuration. The parameters of the PV array configurations are performed in MATLAB/Simulink software.

\section{TCT configuration}

A 9×9 PV array connected in TCT topology is considered for the study [5]. A TCT configuration is achieved by a simple connection of the PV module to its adjacent PV module. All the PV modules are then cross-connected. The PV array consists of 81 modules with nine columns and nine rows. The PV modules are labelled as pq where $\mathrm{p}$ denotes the row and $\mathrm{q}$, the column in which the module is attached. For example, the PV module 99 represents the module located in the nine row and nine columns.

\section{Proposed MSV configuration of PV systems}

The proposed MSV method inspired from a magic square puzzle of order $n=9$, is pattern of $n^{2}$ numbers, and usually different integers, in a square, such that the n numbers in all rows, all columns, and both diagonals sum to the same constant. in this paper we have used for the study the MSV pattern shown in Figure 1. An MSV includes the positive integers from 1 to $n^{2}$. The 
constant sum in every row, column and diagonal is called the magic constant, M. The physical positions of the PV panels are moved without moving the electrical connections in the PV array as have done to the Sudoku SDK configuration [3], [5]. Thus, this method enables to minimize the shading of the panels in the same row and spread the shading over the whole array. Thus, the MSV pattern improves the current entering a node under partial shading conditions and decreases the power losses.

\begin{tabular}{|c|c|c|c|c|c|c|c|c|}
\hline 35 & 25 & 15 & 5 & 76 & 66 & 56 & 46 & 45 \\
\hline 24 & 14 & 4 & 75 & 65 & 55 & 54 & 44 & 34 \\
\hline 13 & 3 & 74 & 64 & 63 & 53 & 43 & 33 & 23 \\
\hline 2 & 73 & 72 & 62 & 52 & 42 & 32 & 22 & 12 \\
\hline 81 & 71 & 61 & 51 & 41 & 31 & 21 & 11 & 1 \\
\hline 70 & 60 & 50 & 40 & 30 & 20 & 10 & 9 & 80 \\
\hline 59 & 49 & 39 & 29 & 19 & 18 & 8 & 79 & 69 \\
\hline 48 & 38 & 28 & 27 & 17 & 7 & 78 & 68 & 58 \\
\hline 37 & 36 & 26 & 16 & 6 & 77 & 67 & 57 & 47 \\
\hline
\end{tabular}

Figure. 1. The MSV Pattern.

\section{Results and Discussion}

A 9X9 PV array is connected in TCT configuration and subjected to Short Wide shading patterns to evaluate the performance of the MSV based configuration method. The results are performed by simulating the different reconfiguration techniques in MATLAB/Simulink environment. PV of $80 \mathrm{~W}$ panel is used for simulation [6] . The results obtained are compared with TCT configuration techniques for the giving shading patterns. Further PV curves are also plotted for comparative analysis of TCT and proposed MSV based reconfiguration technique. Short Wide Shadow:

A PV array is divided into four groups of different insolation. The groups receive an irradiation of $900 \mathrm{~W} / \mathrm{m}^{2}, 600 \mathrm{~W} / \mathrm{m}^{2}, 400 \mathrm{~W} / \mathrm{m}^{2}$ and $200 \mathrm{~W} / \mathrm{m}^{2}$, respectively. Since all the columns and only a few numbers of rows are subjected to shading therefore this shading pattern is referred to as Short Wide.

Figure. 2. Shows the P-V characteristics of TCT and MSV for short wide pattern. 


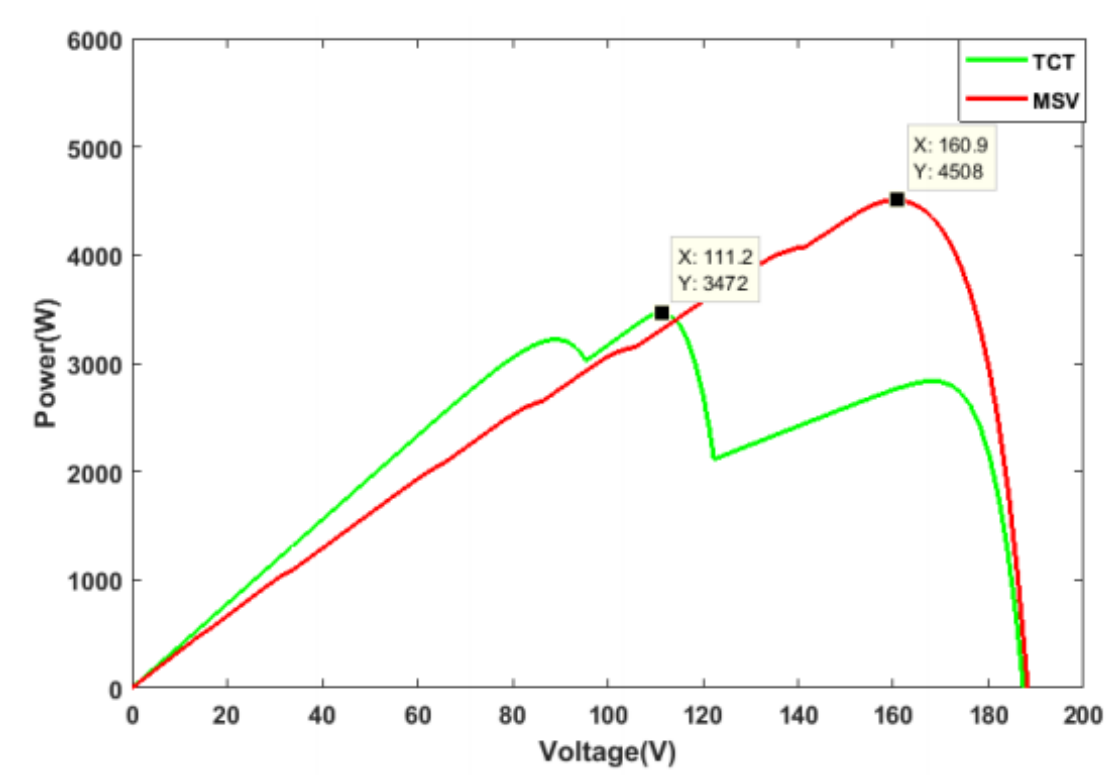

Figure. 2. P-V characteristics of TCT and MSV for short wide pattern Pattern.

It can be seen from the Figure. 2 the MSV configuration reached a maxim power of 4508 at $160 \mathrm{~V}$ and TCT achieved a maximum power of 3472 at $111 \mathrm{~V}$. Further, we can see that there is an increase of $1056,03 \mathrm{~W}$ in output power for MSV method compared to TCT configuration. This amounts to $25.04 \%$ percentage improvement, which is quite significant. Moreover, we can see in Figure. 2 that the MSV the P-V characteristics are more linear and the Global peak is clearer compared to the that TCT has multiple local peaks. Hence, arranging the PV modules according to MSV pattern, enhance the power generated from the array.

As observed from Figure. 2, in this case of short Wide the power produced by the proposed MSV configuration is higher compared to TCT configuration and it is clear exhibited in P-V curves Figure. 2.

\section{Conclusions}

This paper presents the proposed MSV configuration for the arrangement of PV panels in a PV array, which presents an enhancement in the output power of PV configurations under Short Wide pattern. In this technique, the physical location of the PV modules in the PV array is readjusted according to the MSV pattern without changing the electrical connection. The MSV configuration disperses the concentrated shading over the entire PV modules and decreases the mismatch losses of modules compared the configuration TCT. Thus, MSV technique ameliorate the generated PV power better than TCT configuration. The performance of the system is analysed, and it is proved that the proposed technique allows us better results as compared to the TCT schemes. 


\section{IMAT3E'18}

International Meeting on Advanced Technologies in Energy and Electrical

\section{Engineering}

\section{References}

1 "Performance enhancement of partially shaded PV array using novel shade dispersion effect on magic-square puzzle configuration," Sol. Energy, vol. 144, pp. 780-797, Mar. 2017.

2 "A novel cross diagonal view configuration of a PV system under partial shading condition," Sol. Energy, vol. 158, pp. 760-773, Dec. 2017.

3 "Enhancing the Performances of PV Array Configurations Under Partially Shaded Conditions: A Comparative Study,” Int. J. Renew. Energy Res., vol. 8, no. 3, pp. 17791790, Sep. 2018.

$4 \quad$ "A novel Zig-Zag scheme for power enhancement of partially shaded solar arrays," Sol. Energy, vol. 135, pp. 92-102, Oct. 2016.

5 "Enhanced Energy Output From a PV System Under Partial Shaded Conditions Through Artificial Bee Colony,” IEEE Trans. Sustain. Energy, vol. 6, no. 1, pp. 198-209, Jan. 2015.

6 “An Improved Maximum Power Point Tracking for Photovoltaic Grid-Connected Inverter Based on Voltage-Oriented Control,” IEEE Trans. Ind. Electron., vol. 58, no. 1, pp. 66-75, Jan. 2011. 